\title{
Correlating the speed of sound with the Gibbs energy and estimating the speed of sound in fatty acid methyl ester and biodiesel
}

Apinya Cheewaphan ${ }^{1}$, Ubol Chuensumran ${ }^{2}$, Suriya Phankosol $^{3}$, Kornkanok Aryusuk ${ }^{1}$, Supathra Lilitchan ${ }^{4}$, and Kanit Krisnangkura ${ }^{5}$

${ }^{1}$ King Mongkut's University of Technology Thonburi

${ }^{2}$ Suan Dusit University

${ }^{3}$ Bansomdejchaopraya Rajabhat University

${ }^{4}$ Mahidol University

${ }^{5}$ King Mongkut's University of Technology Thonburil

August 31, 2020

\begin{abstract}
The relation between the speed of sound ( $\mathrm{u}$ ) in biodiesel and the change in Gibbs energy (?G) has not been described in the literature. With the method of Gibbs energy additivity, the relation between $\mathrm{u}$ and ? G can be expressed as $\ln (\mathrm{u} 2)=$ ? G/RT + $A$, where $\mathrm{R}$ is the universal gas constant, $\mathrm{T}$ is the absolute temperature, and $\mathrm{A}$ is a constant. Further expansion of ?G into its enthalpy and entropy, and sub-dividing the molecule of a fatty and methyl ester (FAME) into groups of atoms, the final model is good for estimating the speed of sound in both FAME and biodiesel at various temperatures. Only the numbers of double bonds and carbon atoms of the fatty acid are required for the calculation.
\end{abstract}

\section{Hosted file}

Speed of sound R1.docx available at https://authorea.com/users/342701/articles/478525correlating-the-speed-of-sound-with-the-gibbs-energy-and-estimating-the-speed-of-soundin-fatty-acid-methyl-ester-and-biodiesel

\section{Hosted file}

Response_to_reviewers (1).docx available at https://authorea.com/users/342701/articles/ 478525-correlating-the-speed-of-sound-with-the-gibbs-energy-and-estimating-the-speed-ofsound-in-fatty-acid-methyl-ester-and-biodiesel 


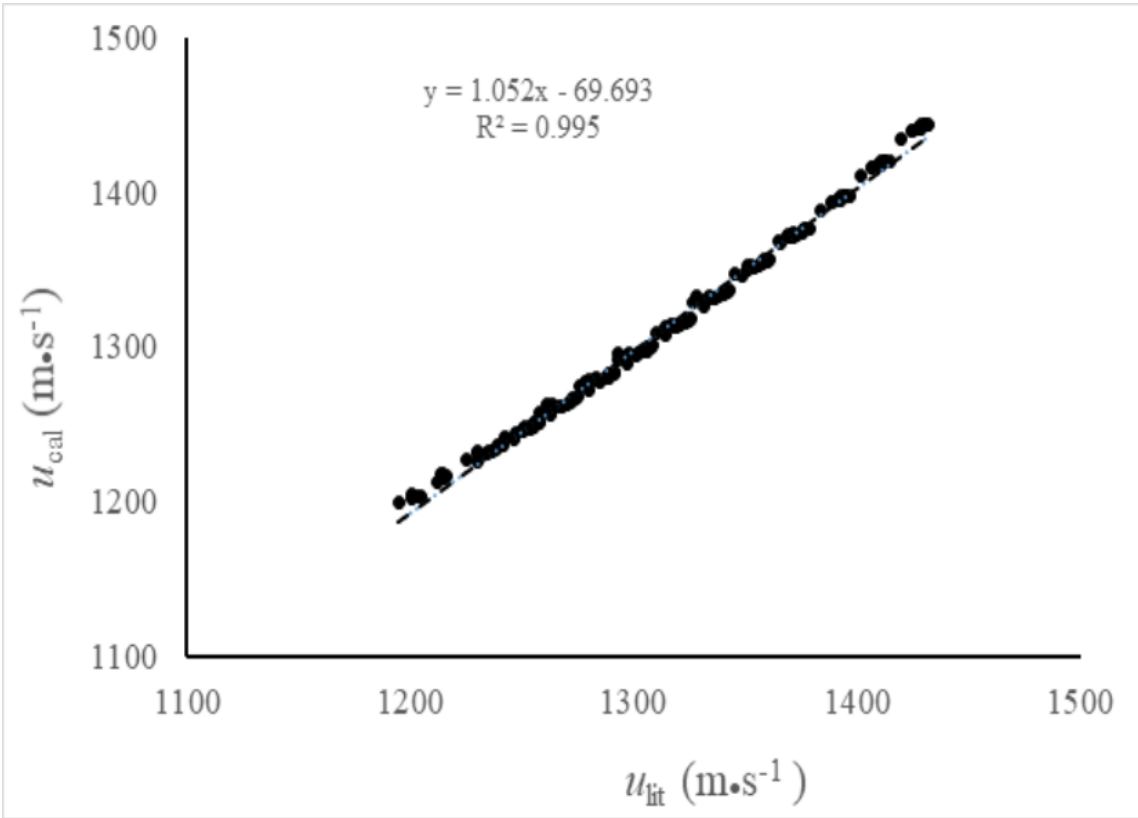

